\title{
Anthropometric and clinical correlates of fat mass in healthy term infants at 6 months of age
}

\author{
Ameyalli M. Rodríguez-Cano1, Jennifer Mier-Cabrera', Cinthya Muñoz-Manrique', Arturo Cardona-Pérez³, \\ Gicela Villalobos-Alcázar ${ }^{2}$ and Otilia Perichart-Perera ${ }^{1 *}$ (iD
}

\begin{abstract}
Background: Body composition in infancy plays a central role in the programming of metabolic diseases. Fat mass (FM) is determined by personal and environmental factors. Anthropometric measurements allow for estimations of FM in many age groups; however, correlations of these measurements with FM in early stages of life are scarcely reported. The aim of this study was to evaluate anthropometric and clinical correlates of FM in healthy term infants at 6 months of age.

Methods: Healthy term newborns $(n=102)$ from a prospective cohort. Weight, length, skinfolds (biceps, triceps, subscapular and the sum -SFS-) and waist circumference (WC) were measured at 6 months. Body mass index (BMI) and WC/length ratio were computed. Type of feeding during the first 6 months of age was recorded. Air displacement plethysmography was used to asses FM (percentage -\%-) and FM index (FMI) was calculated. Correlations and general linear models were performed to evaluate associations.
\end{abstract}

Results: Significant correlations were observed between all anthropometric measurements and FM (\% and index) $(p<0.001)$. Exclusive/predominant breastfed infants had higher FM and anthropometric measurements at 6 months. Models that showed the strongest associations with FM (\% and index) were SFS + WC + sex + type of feeding.

Conclusions: Anthropometry showed good correlations with FM at 6 months of age. Skinfolds sum and waist circumference were the strongest anthropometric variables associated to FM. Exclusive/predominant breastfeeding was strongly associated with FM.

Keywords: Body composition, Air displacement plethysmography, Fat Mass Index, Skinfolds, Adiposity, Hispanic, Type of feeding

\section{Background}

Worldwide increasing prevalence of overweight and obesity among children has highlighted the need for better strategies in its early detection and prevention. The 2013 Global Burden of Disease Study showed a rise of $47 \%$ in overweight and obesity prevalence in children since 1980 [1]. Maternal factors, such as pre-gestational obesity and gestational weight gain, have been identified to influence the risk of obesity and the development of fat mass (FM) in the offspring [2]. Postnatal environmental factors, such

\footnotetext{
* Correspondence: otiliaperichart@inper.gob.mx

${ }^{1}$ Nutrition and Bioprogramming Department, Instituto Nacional de Perinatología "Isidro Espinosa de los Reyes", Montes Urales 800, Col. Lomas de Virreyes, 11000 Ciudad de México, CP, Mexico

Full list of author information is available at the end of the article
}

as type of feeding (breastfeeding vs formula) and duration of breastfeeding, have been recognized as determinants of body composition in infants $[3,4]$. Some authors have reported that exclusively breastfed infants appear to have higher body fat when compared to formula fed ones during the first 6 months of age [5-7].

Because body composition in early infancy could play a central role in the programming of metabolic diseases $[8,9]$, accurate measurement of FM should be part of an infant's nutrition assessment since birth and throughout life [10-12]. Air displacement plethysmography (ADP) is a valid method for assessing FM in infants [13, 14]. However, since ADP is not widely accessible and is often not practical, the estimation of body composition is generally performed through surrogate methods. Anthropometric measurements have

(c) The Author(s). 2019 Open Access This article is distributed under the terms of the Creative Commons Attribution 4.0 International License (http://creativecommons.org/licenses/by/4.0/), which permits unrestricted use, distribution, and reproduction in any medium, provided you give appropriate credit to the original author(s) and the source, provide a link to the Creative Commons license, and indicate if changes were made. The Creative Commons Public Domain Dedication waiver (http://creativecommons.org/publicdomain/zero/1.0/) applies to the data made available in this article, unless otherwise stated. 
been widely used in other age groups because it is a relatively easy, simple and inexpensive alternative for estimating adiposity in clinical settings $[11,15]$. There are few data about the association of anthropometry and FM estimation in the first 6 months of age [16-18].

Weight-for-length (W/L) and body-mass-index for age (BMI/A) are anthropometric indices used for the diagnosis of overweight and obesity in children [19]. The evidence shows that these are valid indicators to estimate body fat in school-age children and adolescents [20-22], but it remains unclear about their use in infants.

Therefore, the aim of this study was to evaluate how anthropometric measurements and clinical factors correlate with FM at 6 months of age in healthy term Mexican infants.

\section{Methods}

\section{Study settings}

This descriptive study derives from a prospective cohort of pregnant women conducted at the National Institute of Perinatology (Mexico City, 2009-2012).

\section{Subjects' recruitment}

We consecutively selected women in their first trimester of pregnancy $(<14$ weeks), who did not have comorbidities (diabetes mellitus, renal, hepatic and/or autoimmune diseases), did not use medication that affected metabolism (metformin, prednisone, etc.) and did not have multiple pregnancies. All adult women that accepted to participate signed an informed consent; for those $<19$ years old, the consent of parents was also required. Women were followed monthly until the end of pregnancy.

\section{Participants' selection}

Newborns were selected by convenience from healthy mothers participating in the afore-mentioned cohort. We invited to participate only those mother-baby binomials that did not develop gestational diabetes or preeclampsia and whose babies were born at the institutional hospital. We included healthy term newborns ( $\geq 37$ weeks). Those babies born prematurely $(<37$ weeks) or with congenital/metabolic diseases were excluded. Babies that lacked body composition assessment at 6 months were eliminated from the analysis.

\section{Anthropometry}

A nutritionist with prior experience and adequately trained in anthropometric measurement standardization performed all the babies' anthropometric procedures at birth (first $72 \mathrm{~h}$ ) and at 6 months of age, following the methods described by Lohman [23].

Infants were measured without clothes. The average of two measurements was recorded, except for weight and FM. At birth, weight was recorded in grams to the nearest $0.1 \mathrm{~kg}$ using a pediatric scale (1582 Baby/Mommy
Scale, TANITA Corp., Tokyo, Japan). Low birth weight $(<2500 \mathrm{~g})$ and macrosomia $(>4000 \mathrm{~g})$ were recorded. At 6 months, weight was measured using the digital scale from the PEAPOD Infant Body Composition System (software version 3.1.0, Lifestyle Measurement Instruments, COSMED, California, USA). Recumbent length was measured to the nearest $0.1 \mathrm{~cm}$ using an infantometer (SECA 207, SECA, Hamburg, Germany). With the help of a nurse, the infant was laid down and her/his head was placed in the Frankfort plane (as the best anatomical indicator of a physiological position for a population without facial deformities) [24]. Length was measured from the crown of the head to the foot's heel, while both were appropriately attached to the infantometer. BMI was computed (weight/length ${ }^{2}$ ) and sex-specific $\mathrm{z}$-scores for $\mathrm{BMI} / \mathrm{A}$ and $\mathrm{W} / \mathrm{L}$ were calculated using the World Health Organization (WHO) Anthro software program (version 3.0.1, WHO, Geneva, Switzerland). Risk of overweight ( $>1$ standard deviation scores), overweight ( $>2$ standard deviation scores) and obesity (> 3 standard deviation scores) was defined based on z-scores.

Waist circumference (WC) was measured around the umbilicus to the nearest $0.1 \mathrm{~cm}$ with a fiberglass anthropometric measuring tape (Gulick, Sammons Preston, Chicago, USA). WC-to-length ratio (WLR) was obtained dividing WC by length.

Skinfolds (biceps -BSF-, triceps -TSF- and subscapular -SSF) were measured with a Lange caliper (Beta Technology, California, USA) from the child's left arm holding the skin between the index finger and thumb (one centimeter above the measurement site) while the baby was laid down. BSF and TSF were measured taking as reference the mid-point of the arm grasping the skin parallel to the floor. SSF was taken at a $45^{\circ}$ to the horizontal plane. A difference $>2 \mathrm{~mm}$ between both measurements required a third measurement. Skinfold sum (SFS) was obtained by adding the values from the three skinfolds aforementioned.

\section{Fat mass (FM\% and FMI)}

The assessment of FM (percentage -\%- and kilograms -kg-) and fat-free mass (FFM, \% and $\mathrm{kg}$ ) was performed at 6 months using the PEAPOD Infant Body Composition System $[25,26]$. Every day, before starting measurements, the PEAPOD was calibrated according to the manufacturer's protocol. Before placing the infant in the PEAPOD scale, (s) he was undressed and a head cap was put on to minimize air trapped in the hair. Then, (s) he was placed in the test chamber tray in order to start with the measurement of body composition. After volume and weight were measured by de PEAPOD, the system's software calculated the infant's body composition based on Fomon's body density values. FMI 
(FMkg/length ${ }^{2}$ ) was computed to correct for variations in FM related to body size [27].

\section{Feeding practices assessment}

At 1-, 3- and 6-months-old visits, mothers were asked a series of questions regarding their infant's feeding practices.
Using the information collected from the 6-months questionnaire, infants were classified within 3 breastfeeding categories according to the $\mathrm{WHO}$ definition [28]: a) exclusive and predominant breastfed for 6 months (E/P BF), b) breastfed for up to 6 months + formula feeding $(\mathrm{BF}+\mathrm{F})$, and $\mathrm{c})$ breastfed for less than 6 months + formula feeding $(\mathrm{BF}<6 \mathrm{~m}+\mathrm{F})$.

Table 1 Descriptive data of mothers, newborns and infants at 6 months

\begin{tabular}{|c|c|c|c|}
\hline Maternal information & $\operatorname{ALL}(n=102)$ & GIRLS $(n=53)$ & BOYS $(n=49)$ \\
\hline Age (years) & $28.5(14-44)$ & $23(14-40)^{\#}$ & $32(14-44)^{\#}$ \\
\hline Pre-gestational weight (kg) & $59(50.4-68)$ & $58.0(50.0-68.8)$ & $60.0(53.5-67.5)$ \\
\hline Height (cm) & $156.7 \pm 5.8$ & $156.7 \pm 6.6$ & $156.8 \pm 4.9$ \\
\hline Pre-gestational BMI (kg/m²) & $23.9(15.1-48.4)$ & $23.3(15.1-35.3)$ & $24.6(18.4-48.1)$ \\
\hline Overweight/obesity & $41(40.2)$ & $19(35.8)$ & $22(44.9)$ \\
\hline GWG (3rd trimester) & $n=92$ & $n=49$ & $n=43$ \\
\hline Adequate & $22(23.9)$ & $10(20.4)$ & $12(27.9)$ \\
\hline Excessive & $43(46.7)$ & $23(46.9)$ & $20(46.5)$ \\
\hline Infant anthropometry @ birth & $n=94$ & $n=49$ & $n=45$ \\
\hline Weight (kg) & $2.89 \pm 0.35$ & $2.81 \pm 0.32^{*}$ & $2.98 \pm 0.35^{*}$ \\
\hline Length (cm) & $46.9 \pm 2.0$ & $46.4 \pm 1.9^{*}$ & $47.5 \pm 1.9^{*}$ \\
\hline BMI $\left(\mathrm{kg} / \mathrm{m}^{2}\right)$ & $13.1 \pm 1.0$ & $13.1 \pm 1.0$ & $13.0 \pm 1.1$ \\
\hline BMI/A (z-score) & $-0.20 \pm 0.84$ & $-0.16 \pm 0.79$ & $-0.26 \pm 0.90$ \\
\hline W/L (z-score) & $0.31 \pm 0.95$ & $0.39 \pm 0.87$ & $0.26 \pm 1.03$ \\
\hline Infant anthropometry @ 6 months & $n=102$ & $n=53$ & $n=49$ \\
\hline Weight (kg) & $7.13 \pm 0.86$ & $6.91 \pm 0.81^{*}$ & $7.47 \pm 0.86^{*}$ \\
\hline Length $(\mathrm{cm})$ & $64.0 \pm 2.6$ & $63.1 \pm 2.2$ & $65.0 \pm 2.6$ \\
\hline $\mathrm{BMI}\left(\mathrm{kg} / \mathrm{m}^{2}\right)$ & $17.4 \pm 1.6$ & $17.3 \pm 1.6$ & $17.4 \pm 1.6$ \\
\hline BMI/A (z-score) & $0.10 \pm 1.1$ & $0.22 \pm 1.00$ & $-0.02 \pm 1.18$ \\
\hline W/L (z-score) & $0.26 \pm 1.1$ & $0.40 \pm 1.00$ & $0.12 \pm 1.18$ \\
\hline Waist circumference $(\mathrm{cm})$ & $39.4 \pm 2.7$ & $39.2 \pm 2.7$ & $39.7 \pm 2.8$ \\
\hline Triceps skinfold (mm) & $8.0(7.0-9.5)$ & $8.0(7.0-9.0)$ & $8.0(7.0-10.0)$ \\
\hline Biceps skinfold (mm) & $6.0(5.0-7.0)$ & $6.0(4.0-7.0)$ & $6.0(5.0-7.0)$ \\
\hline Subscapular skinfold (mm) & $7.0(6.0-9.0)$ & $7.0(6.0-9.0)$ & $7.0(6.5-8.0)$ \\
\hline Skinfolds sum (mm) & $21(18.0-24.5)$ & $21(18.0-23.5)$ & $21(18.5-25.0)$ \\
\hline Fat mass (\%) & $25.8 \pm 5.9$ & $26.0 \pm 6.4$ & $25.5 \pm 5.5$ \\
\hline Fat mass (kg) & $1.9 \pm 0.6$ & $1.8 \pm 0.6$ & $1.9 \pm 0.5$ \\
\hline FMI (FMkg/length²) & $4.5 \pm 1.4$ & $4.5 \pm 1.5$ & $4.5 \pm 1.2$ \\
\hline Fat-free mass (\%) & $74.2 \pm 5.9$ & $74.0 \pm 6.4$ & $74.5 \pm 5.5$ \\
\hline Fat-free mass (kg) & $5.3 \pm 0.6$ & $5.1 \pm 0.5^{* *}$ & $5.5 \pm 0.5^{* *}$ \\
\hline Feeding information @ 6 months & $n=102$ & $n=53$ & $n=49$ \\
\hline Exclusive/predominant breastfeeding & $26(25.5)$ & $13(24.5)$ & $13(26.5)$ \\
\hline Breastfeeding up to 6 months + formula & $47(46.1)$ & $22(41.5)$ & $25(51.0)$ \\
\hline Breastfeeding $<6$ months + formula & $29(28.4)$ & $18(34.0)$ & $11(22.4)$ \\
\hline Started complementary feeding $<4$ month & $25(24.8)$ & $15(28.3)$ & $10(20.8)$ \\
\hline Started complementary feeding $>4$ month & $76(75.2)$ & $38(71.7)$ & $38(79.2)$ \\
\hline
\end{tabular}

Data are shown as Mean \pm SD; Median $\left(25^{\circ}-75^{\circ}\right) ; n(\%)$

$B M I$ Body mass index, GWG, Gestational weight gain, BMI/A Body-mass-index/age, W/L, weight-to-length, FMI Fat mass index, FMkg kilograms of fat mass T-Student test ${ }^{*} p<0.05 ;{ }^{* *} p=0.001$ (girls vs boys); ${ }^{*} \mathrm{U}$ Mann-Whitney test $p<0.05$ (girls vs boys) 


\section{Maternal information}

Mothers participating in the cohort study reported their age and pre-gestational weight in their first visit. Pre-gestational BMI was computed and classified according to WHO criteria (low, normal, overweight or obesity).

\section{Statistical analysis}

Descriptive statistics and frequencies were performed for all variables. Mean differences were analyzed using Student's t-test for parametric variables or U Mann-Whitney for non-parametric ones. One-way ANCOVA was performed to evaluate differences in anthropometric indices and FM according to type of feeding. Pearson's and Spearman's correlations were used to evaluate bivariate associations between FM (\% and index) and anthropometric measures.

General linear models were performed to evaluate the association of anthropometric measurements (TSF, BSF, SSF, SFS, WC and length) and clinical factors with FM (\% and index) at 6 months. The dependent variable was FM\% or FMI; independent variables included sex and type of feeding. For FM\% models, length was considered as a variable, and excluded in FMI models. A $p$-value $<0.05$ was considered statistically significant. Statistics were performed with the IBM SPSS Software (version 22, SPSS Statistics/IBM Corp, New York, USA).

\section{Results}

\section{Participants' characteristics}

A total of 222 healthy mother-baby binomials from the cohort study were recruited following birth and invited to participate. Nevertheless, only 155 agreed to participate. Fifty-three infants that lacked body composition measurement at 6 months were eliminated. This analysis included a total of 102 infants. Due to different circumstances not attributable to our staff, it was not possible to assess weight and length of eight infants at birth $(n=94)$ (Table 1).
Mothers had a mean age of $27.1 \pm 8.7$ years and their mean pre-gestational BMI was $24.7 \pm 5.2 \mathrm{~kg} / \mathrm{m}^{2}$. The prevalence of pre-gestational overweight/obesity was $40.2 \%$. At birth, infants' mean gestational age, weight and length was $39.0 \pm 1.1$ weeks, $2.89 \pm 0.35 \mathrm{~kg}$ and $46.9 \pm 2.0$ $\mathrm{cm}$, respectively. Low birth weight was present in $10.6 \%$ $(n=10)$ of newborns and no infants were classified as macrosomic. Most of the newborns had normal BMI/A at birth $(93.4 \%, n=95)$, and there were no infants classified with obesity during the first 6 months of age.

Descriptive data of mothers, newborns and infants at 6 months is presented in Table 1. Boys had a higher weight and length at birth, as well as a higher weight and FFM at 6 months $(p<0.05)$. No other anthropometric differences were observed by sex $(p>0.05)$.

\section{Type of feeding, anthropometry and FM}

FM (\% and $\mathrm{kg}$ ) was higher and FFM (\% and $\mathrm{kg}$ ) was lower in infants classified as $\mathrm{E} / \mathrm{P} \mathrm{BF}$ when compared to $\mathrm{BF}+\mathrm{F}$ or $\mathrm{BF}<6 \mathrm{~m}+\mathrm{F}$. Except for WC, all anthropometric measurements were higher in the $\mathrm{E} / \mathrm{P}$ BF group (adjusted by sex, BMI/A at birth and pre-gestational BMI) (Table 2).

\section{FM and anthropometric associations}

Correlations of anthropometric measurements with FM\% at 6 months were all statistically significant $(p<0.001)$. The strongest correlation coefficients were for BMI $(r=0.691)$, SFS $(r=0.603)$ and WC $(r=0.591)$, followed by WLR $(r=0.589)$, SSF $(\mathrm{r}=0.588)$ and TSF $(r=0.581)$. The weakest correlations were for weight $(r=0.569)$ and BSF $(r=0.409)$.

All anthropometric measurements had significant correlations with FMI $(p<0.0001)$. In order of strength, correlation coefficients were as follows: BMI $(r=0.816)$, WLR $(r=0.693)$, WC $(\mathrm{r}=0.691)$, weight $(r=0.668)$, SFS $(r=0.640)$, SSF $(\mathrm{r}=0.631)$, TSF $(\mathrm{r}=0.624)$ and BSF $(r=0.415)$.

Table 2 Fat mass and anthropometric data according to type of feeding in infants at 6 months

\begin{tabular}{lllll}
\hline & $\begin{array}{l}\text { All } \\
n=102\end{array}$ & $\begin{array}{l}\text { Exclusive/predominant Breastfeeding } \\
n=26\end{array}$ & $\begin{array}{l}\text { Breastfeeding up to 6 months + Formula } \\
n=47\end{array}$ & $\begin{array}{l}\text { Breastfeeding } \\
<6 \text { months + Formula } \\
n=29\end{array}$ \\
\hline BMI (kg/m $\left.{ }^{2}\right)$ & $17.4 \pm 1.6$ & $17.8 \pm 2.0$ & $17.3 \pm 1.3$ & $17.1 \pm 1.6^{\mathrm{a}}$ \\
Waist circumference (cm) & $39.4 \pm 2.7$ & $40.0 \pm 3.1$ & $39.3 \pm 2.8$ & $39.1 \pm 2.2$ \\
Triceps skinfold (mm) & $8.1 \pm 1.9$ & $8.6 \pm 2.2$ & $7.7 \pm 1.6^{\mathrm{a}}$ & $8.2 \pm 1.9$ \\
Skinfolds sum (mm) & $21.6 \pm 4.5$ & $23.2 \pm 5.7$ & $20.9 \pm 3.6^{\mathrm{a}}$ & $21.3 \pm 4.4^{\mathrm{a}}$ \\
Fat mass (\%) & $25.8 \pm 5.9$ & $29.4 \pm 5.6$ & $24.9 \pm 5.8^{\mathrm{b}}$ & $23.9 \pm 5.2^{\mathrm{c}}$ \\
Fat mass (kg) & $1.9 \pm 0.6$ & $2.1 \pm 0.6$ & $1.8 \pm 0.6^{\mathrm{b}}$ & $1.7 \pm 0.4^{\mathrm{a}}$ \\
FMl (FMkg/length $\left.{ }^{2}\right)$ & $4.5 \pm 1.4$ & $5.3 \pm 1.5$ & $4.3 \pm 1.3^{\mathrm{b}}$ & $4.2 \pm 1.1^{c}$ \\
\hline
\end{tabular}

Data are shown as Mean \pm SD

One-way ANCOVA. LSD post hoc test. ${ }^{\mathrm{a}} p<0.05,{ }^{\mathrm{b}} p<0.01$ and ${ }^{\mathrm{c}} p<0.001$ vs Exclusive/predominant breastfeeding

Model adjusted by sex, BMI/A (z-score) at birth and pre-gestational BMI $\left(\mathrm{kg} / \mathrm{m}^{2}\right)$

$B M I$ Body mass index, FMI Fat mass index, FMkg kilograms of fat mass 
Table 3 Correlates of FM\% in infants at 6 months

\begin{tabular}{|c|c|c|c|c|c|}
\hline Variable & B & IC 95\% & Eta partial squared & $p$ & $\begin{array}{l}R^{2} \\
\left(R^{2} \text { adjusted) }\right.\end{array}$ \\
\hline \multicolumn{5}{|l|}{ Model 1} & \multirow{7}{*}{$\begin{array}{c}0.500 \\
(0.463)\end{array}$} \\
\hline Skinfolds sum & 0.823 & $0.611-1.035$ & 0.387 & $<0.0001$ & \\
\hline Length & 0.209 & $-0.164-0.582$ & 0.013 & 0.268 & \\
\hline Sex [female] & 3.844 & $0.415-7.272$ & 0.050 & 0.028 & \\
\hline Exclusive/Predominant Breastfeeding & 6.399 & $2.809-9.988$ & 0.118 & 0.001 & \\
\hline Breastfeeding up to 6 months + Formula & 3.740 & $0.572-6.907$ & 0.055 & 0.021 & \\
\hline Breastfeeding $<6$ months + Formula & Reference & & & & \\
\hline \multicolumn{5}{|l|}{ Model 2} & \multirow{8}{*}{$\begin{array}{c}0.552 \\
(0.513)\end{array}$} \\
\hline Skinfold sum & 0.572 & $0.319-0.825$ & 0.178 & $<0.0001$ & \\
\hline Waist circumference & 0.720 & $0.283-1.157$ & 0.103 & 0.002 & \\
\hline Length & -0.090 & $-0.489-0.309$ & 0.002 & 0.654 & \\
\hline Sex [female] & 3.203 & $-0.085-6.492$ & 0.039 & 0.056 & \\
\hline Exclusive/Predominant Breastfeeding & 5.960 & $2.531-9.388$ & 0.114 & 0.001 & \\
\hline Breastfeeding up to 6 months + Formula & 2.964 & $-0.088-6.107$ & 0.038 & 0.057 & \\
\hline Breastfeeding $<6$ months + Formula & Reference & & & & \\
\hline \multicolumn{5}{|l|}{ Model 3} & \multirow{7}{*}{$\begin{array}{c}0.443 \\
(0.401)\end{array}$} \\
\hline Triceps Skinfold & 1.746 & $1.220-2.271$ & 0.316 & $<0.0001$ & \\
\hline Length & 0.301 & $-0.090-0.692$ & 0.024 & 0.130 & \\
\hline Sex [female] & 3.862 & $0.223-7.500$ & 0.045 & 0.038 & \\
\hline Exclusive/Predominant Breastfeeding & 6.292 & $2.498-10.087$ & 0.103 & 0.001 & \\
\hline Breastfeeding up to 6 months + Formula & 4.164 & $0.784-7.543$ & 0.060 & 0.016 & \\
\hline Breastfeeding $<6$ months + Formula & Reference & & & & \\
\hline \multicolumn{5}{|l|}{ Model 4} & \multirow{8}{*}{$\begin{array}{c}0.531 \\
(0.491)\end{array}$} \\
\hline Triceps Skinfold & 1.117 & $0.547-1.686$ & 0.140 & $<0.0001$ & \\
\hline Waist circumference & 0.883 & $0.464-1.303$ & 0.158 & $<0.0001$ & \\
\hline Length & -0.102 & $-0.510-0.307$ & 0.003 & 0.622 & \\
\hline Sex [female] & 3.105 & $-0.271-6.842$ & 0.035 & 0.071 & \\
\hline Exclusive/Predominant Breastfeeding & 5.820 & $2.312-9.328$ & 0.105 & 0.001 & \\
\hline Breastfeeding up to 6 months + Formula & 3.086 & $-0.074-6.246$ & 0.039 & 0.055 & \\
\hline Breastfeeding $<6$ months + Formula & Reference & & & & \\
\hline
\end{tabular}

$n=102$ infants; FM\%: Fat mass percentage

The strongest models of FM\% included SFS + WC + length (model 2) followed by TSF + WC + length (Model 4) (Table 3). Regarding FMI, the strongest associations were shown for SFS + WC (model 2) followed by TSF + WC (Model 4) (Table 4).

\section{Discussion}

This is one of the few studies measuring FM at 6 months of age using ADP in a group of healthy term infants. Our results showed that anthropometric measurements are highly correlated with FM in infants. SFS and WC were strongly associated to FM.

In our study, the model that best correlated anthropometry to FM at 6 months of age included SFS +
WC. We observed that when more anthropometric variables were included in the model, the strength of the association with FM improved, as other authors have reported [18, 22].

The increase in the prevalence of childhood overweight and obesity worldwide has encouraged the study of body composition during early stages of life $[29,30]$. In Mexico, the prevalence of overweight/obesity in children has been increasing over the years, where one out of every three children (5-11 years old) has this problem [31]. Weight is still the most frequently used indicator in clinical practice to evaluate growth and morbidity in this age group. FM measurement should be the basis for obesity diagnosis and to identify metabolic risk. Early 
Table 4 Correlates of FMI in infants at 6 months

\begin{tabular}{|c|c|c|c|c|c|}
\hline Variable & B & IC 95\% & Eta partial squared & $p$ & $\begin{array}{l}R^{2} \\
\left(R^{2} \text { adjusted) }\right.\end{array}$ \\
\hline \multicolumn{5}{|l|}{ Model 1} & \multirow{6}{*}{$\begin{array}{c}0.561 \\
(0.534)\end{array}$} \\
\hline Skinfolds sum & 0.211 & $0.166-0.256$ & 0.475 & $<0.0001$ & \\
\hline Sex [female] & 0.626 & $-0.103-1.355$ & 0.030 & 0.092 & \\
\hline Exclusive/Predominant Breastfeeding & 1.093 & $0.323-1.863$ & 0.077 & 0.006 & \\
\hline Breastfeeding up to 6 months + Formula & 0.762 & $0.082-1.442$ & 0.049 & 0.029 & \\
\hline Breastfeeding $<6$ months + Formula & Reference & & & & \\
\hline \multicolumn{5}{|l|}{ Model 2} & \multirow{7}{*}{$\begin{array}{c}0.656 \\
(0.631)\end{array}$} \\
\hline Skinfold sum & 0.135 & $0.085-0.185$ & 0.235 & $<0.0001$ & \\
\hline Waist circumference & 0.200 & $0.122-0.279$ & 0.216 & $<0.0001$ & \\
\hline Sex [female] & 0.559 & $-0.091-1.208$ & 0.030 & 0.091 & \\
\hline Exclusive/Predominant Breastfeeding & 1.009 & $0.322-1.695$ & 0.083 & 0.004 & \\
\hline Breastfeeding up to 6 months + Formula & 0.521 & $-0.092-1.133$ & 0.029 & 0.095 & \\
\hline Breastfeeding $<6$ months + Formula & Reference & & & & \\
\hline \multicolumn{5}{|l|}{ Model 3} & \multirow{6}{*}{$\begin{array}{c}0.483 \\
(0.450)\end{array}$} \\
\hline Triceps Skinfold & 0.446 & $0.330-0.562$ & 0.381 & $<0.0001$ & \\
\hline Sex [female] & 0.589 & $-0.205-1.384$ & 0.022 & 0.144 & \\
\hline Exclusive/Predominant Breastfeeding & 1.048 & $0.210-1.885$ & 0.061 & 0.015 & \\
\hline Breastfeeding up to 6 months + Formula & 0.871 & $0.124-1.617$ & 0.053 & 0.023 & \\
\hline Breastfeeding $<6$ months + Formula & Reference & & & & \\
\hline \multicolumn{5}{|l|}{ Model 4} & \multirow{7}{*}{$\begin{array}{c}0.635 \\
(0.608)\end{array}$} \\
\hline Triceps Skinfold & 0.267 & $0.153-0.380$ & 0.189 & $<0.0001$ & \\
\hline Waist circumference & 0.237 & $0.162-0.312$ & 0.295 & $<0.0001$ & \\
\hline Sex [female] & 0.542 & $-0.129-1.213$ & 0.027 & 0.112 & \\
\hline Exclusive/Predominant Breastfeeding & 0.980 & $0.273-1.687$ & 0.075 & 0.007 & \\
\hline Breastfeeding up to 6 months + Formula & 0.553 & $-0.085-1.191$ & 0.031 & 0.088 & \\
\hline Breastfeeding $<6$ months + Formula & Reference & & & & \\
\hline
\end{tabular}

detection of alterations in FM appears critical; therefore, FM should be considered an outcome of nutrition and lifestyle interventions in infancy. Predictions equations using different anthropometric measurements for estimating FM in infants are needed and will facilitate this task in clinical settings.

On the other hand, BMI has been proposed to assess growth and nutritional status because it is known to correlate with body fatness and increases the risk of obesity-related diseases in adults [32, 33]. However, some inherent limitations of BMI are that it does not distinguish between FM and FFM, it does not reflect FM distribution and the relative contributions of FM and FFM to body weight vary by ethnicity [12, 34, 35]. So, there are still concerns about its use in pediatric population $[35,36]$. In older children ( $\geq 7$ years old), authors have found some misclassifications of obesity diagnosis using BMI in comparison to body fatness $[37,38]$. They stated that the screening ability of BMI varied across race-ethnic groups, and also across the extremes of FM [38]. In infants $(1,4$, and 7 months old), Bell et al. [39] found that BMI is limited as a surrogate for adiposity and (especially) adiposity changes. However, there is still controversy [40, 41].

Skinfolds are valid measures of subcutaneous fat and have been used for estimating total body fat in adults, but there is limited information about their validity in childhood and infancy. Bias may be introduced by age, measurement error and error inherent with increasing fatness $[10,32]$. In our study, we observed a strong correlation between SFS (BSF, TSF, SSF) and FM (\% and index). Other authors have reported that skinfolds are good predictors of FM\% in school-age children and, unlike BMI, skinfolds may be useful for both extremes of body fatness [21, 30, 32]. Wohlfahrt-Veje et al. [21] found that FM\% estimation from skinfolds (TSF and SSF) showed the highest correlation and best agreement with $\mathrm{FM} \%$, measured by dual $\mathrm{x}$-ray absorptiometry, and 
was superior at identifying children (8-14 years old) with higher adiposity, as compared to only BMI or WC. Tuan et al. [42] reported a higher agreement between FM and TSF and waist-to-height ratio, rather than between FM and BMI. Our models show a slightly better association of SFS with FM, but when availability of measurements is limited, TSF alone could be useful.

WC is a measurement used to assess central adiposity $[12,16]$. Considering fat distribution indicators could be important for a more comprehensive FM assessment, as it reflects metabolic risk [43]. Santos et al. [44] found that subcutaneous fat (measured by skinfolds) in infancy (1.5 and 24 months) was positively associated to total and abdominal fat at 6 years old. Some authors have identified moderate-strong associations of WC with total body fat $[15,20,45]$, trunk fat in children [22], concluding that WC may be useful to define obesity and to predict relative adiposity in children $[15,46]$. This is important because the estimation of FM\% and FMI improved when WC was included in the models. The skinfolds that we measured represent subcutaneous fat and two of them (BSF and TSF) are measures of peripheral fat. WC is an indirect measure of visceral fat $[12,16]$, so including both type of measurements appears to be ideal.

The use of FMI (when compared to FM\% alone) has been proposed as a more accurate indicator of adiposity and more sensitive to changes in body fat stores [35, 47], even in infants [48], due to the consideration and normalization to height/length [27, 49]. Infants at potential risk (but with "normal" BMI) could be detected using FMI [48] because it better identifies excess adiposity than FM\%, which underestimates it [35]. In our models, stronger associations were found between anthropometry and FMI, in comparison to FM\%.

In our study, infants that were exclusive/predominant breastfed during the first 6 months showed higher FM and anthropometric measurements at 6 months. Some authors have reported higher adiposity in exclusively breastfed infants when compared to those that were formula fed at 3-4 and at 6 months of age [6-8].

This study has some limitations. Fat mass measurement at birth was not feasible, therefore, we have no data to correlate in this stage. It is well known that skinfold measurement may introduce a high measurement error; to decrease it, one nutritionist with previous experience and anthropometric training and standardization performed them by duplicate. The small sample and low prevalence of obesity in this group of infants might limit the associations found in this analysis. Performance of anthropometric measures may differ in the extremes of obesity, as has been shown in adults.

\section{Conclusions}

Anthropometric measurements were good determinants of FM at 6 months of age in healthy term infants.
Skinfolds sum and waist circumference were the strongest anthropometric variables associated to FM. Type of feeding and sex influence body fat in this age group. Exclusive/predominant breastfeeding was strongly associated with FM.

\section{Abbreviations \\ ADP: Air displacement plethysmography; BF + F: Breastfeeding up to 6 months combined with formula feeding; $B F<6 m+F$ : Breastfeeding less than 6 months combined with formula feeding; BMl: Body mass index; BMI/ A: Body-mass-index for age; BSF: Biceps skinfold; E/P BF: Exclusive/ Predominant breastfeeding; FFM: Fat-free mass; FM: Fat mass; FM\%: Fat mass percentage; FMI: Fat mass index; SFS: Skinfolds sum; SSF: Subscapular skinfold; TSF: Triceps skinfold; W/L: Weight-for-length; WC: Waist circumference; WHO: World Health Organization; WLR: Waist circumference- for-length ratio}

\section{Acknowledgments}

Not applicable.

\section{Funding}

This research received no specific grant from any funding agency, commercial or not-for-profit sectors.

\section{Availability of data and materials}

The datasets used and/or analyzed during the current study are available from the corresponding author on reasonable request.

\section{Authors' contributions}

The authors' contributions are as following: the study was designed by OPP. CMM and ARC conducted the data collection examination. OPP formulated the research question. ARC and JMC analyzed the data and wrote the first draft of the manuscript. OPP supervised the quality standards of the statistical analyses. ARC, JMC, OPP, CMM, GVA, and ACP contributed to the interpretation and discussion of the results and commented on the drafts. All authors have read and approved the final manuscript.

\section{Competing interest}

ARC and OPP are speakers of the Nestlé Nutrition Institute in Mexico. There is no conflict of interest of any kind in this manuscript regarding this institution. The rest of the authors declare that they have no competing interests.

\section{Ethics approval and consent to participate}

This study was conducted according to the Declaration of Helsinki and all procedures involving humans were approved by the National Institute of Perinatology's Institutional Review Board and Ethics Committee (reference number: 212250-49511). Written informed consent was obtained from all mothers.

\section{Consent for publication}

Not applicable.

\section{Publisher's Note}

Springer Nature remains neutral with regard to jurisdictional claims in published maps and institutional affiliations.

\section{Author details}

${ }^{1}$ Nutrition and Bioprogramming Department, Instituto Nacional de Perinatología "Isidro Espinosa de los Reyes", Montes Urales 800, Col. Lomas de Virreyes, 11000 Ciudad de México, CP, Mexico. ${ }^{2}$ Neonatal Ward, Instituto Nacional de Perinatología "Isidro Espinosa de los Reyes", Montes Urales 800, Col. Lomas de Virreyes, 11000 Ciudad de México, CP, Mexico. ${ }^{3}$ General Director, Instituto Nacional de Perinatología "Isidro Espinosa de los Reyes", Montes Urales 800, Col. Lomas de Virreyes, 11000 Ciudad de México, CP, Mexico. 


\section{Received: 19 June 2018 Accepted: 11 February 2019} Published online: 18 February 2019

\section{References}

1. Ng M, Fleming T, Robinson M, Thomson B, Graetz N, Margono C, et al. Global, regional, and national prevalence of overweight and obesity in children and adults during 1980-2013: a systematic analysis for the global burden of disease study 2013. Lancet. 2014;384:766-81.

2. Au CP, Raynes-Greenow $\mathrm{CH}$, Turner RM, Carberry $\mathrm{AE}$, Jeffery $\mathrm{H}$. Fetal and maternal factors associated with neonatal adiposity as measured by air displacement plethysmography: a large cross-sectional study. Early Hum Dev. 2013;89:839-43. https://doi.org/10.1016/j.earlhumdev.2013.07.028.

3. Oddy WH, Mori TA, Huang RC, Marsh JA, Pennell CE, Chivers PT, et al. Early infant feeding and adiposity risk: from infancy to adulthood. Ann Nutr Metab. 2014;64:262-70. https://doi.org/10.1159/000365031.

4. Pirilä S, Saarinen-Pihkala U, Viljakainen H, Turanlahti M, Kajosaari M, Mäkitie O, et al. Breastfeeding and determinants of adult body composition: a prospective study from birth to young adulthood. Horm Res Paediatr. 2012;77:281-90.

5. Giannì ML, Roggero P, Morlacchi L, Garavaglia E, Piemontese P, Mosca F. Formula-fed infants have significantly higher fat-free mass content in their bodies than breastfed babies. Acta Paediatr. 2014;103:e277-81. https://doi. org/10.1111/apa.12643

6. Butte NF, Hopkinson JM, Wong WW, Smith EO, Ellis KJ. Body composition during the first 2 years of life: an updated reference. Pediatr Res. 2000;47: 578-85. https://doi.org/10.1203/00006450-200005000-00004.

7. Gale C, Logan KM, Santhakumaran S, Parkinson JR, Hyde MJ, Modi N. Effect of breastfeeding compared with formula feeding on infant body composition: a systematic review and meta-analysis. Am J Clin Nutr. 2012; 95:656-69. https://doi.org/10.3945/ajcn.111.027284.

8. Carberry AE, Colditz PB, Lingwood BE. Body composition from birth to 4.5 months in infants born to non-obese women. Pediatr Res. 2010.

9. Andersen GS, Girma T, Wells JCK, Kæstel P, Leventi M, Hother AL, et al. Body composition from birth to 6 mo of age in Ethiopian infants: reference data obtained by air-displacement plethysmography. Am J Clin Nutr. 2013.

10. Fields DA, Gilchrist JM, Catalano PM, Giannì ML, Roggero PM, Mosca F. Longitudinal body composition data in exclusively breast-fed infants: a multicenter study. Obesity (Silver Spring). 2011.

11. Horan M, Gibney E, Molloy E, McAuliffe F. Methodologies to assess paediatric adiposity. Ir J Med Sci. 2015;184:53-68.

12. Araújo de França G V, Restrepo-Méndez MC, Loret de Mola C, Victora CG. Size at birth and abdominal adiposity in adults: A systematic review and meta-analysis. Obes Rev. 2014;15:77-91.

13. Andersen GS, Girma T, Wells JCK, Kastel P, Michaelsen KF, Friis H. Fat and fat-free mass at birth: air displacement plethysmography measurements on 350 ethiopian newborns. Pediatr Res. 2011;70:501-6.

14. Carberry AE, Raynes-Greenow CH, Turner RM, Askie LM, Jeffery HE. Is body fat percentage a better measure of undernutrition in newborns than birth weight percentiles? Pediatr Res. 2013;74:730-6. https://doi.org/10.1038/pr.2013.156.

15. Martin-Calvo N, Moreno-Galarraga L, Martinez-Gonzalez MA. Association between body mass index. Waist-to-Height Ratio and Adiposity in Children: A Systematic Review and Meta-Analysis Nutrients. 2016;8:512.

16. Holston A, Stokes T, Olsen C, Choi YS, Curtis J, Higginson J, et al. Novel noninvasive anthropometric measure in preterm and full-term infants: normative values for waist circumference:length ratio at birth. Pediatr Res. 2013;74 August:299-306. doi:https://doi.org/10.1038/pr.2013.109.

17. Reilly JJ, Kelly J, Wilson DC. Accuracy of simple clinical and epidemiological definitions of childhood obesity: systematic review and evidence appraisal. Obes Rev. 2010;11:645-55.

18. De Cunto A, Paviotti G, Ronfani L, Travan L, Bua J, Cont G, et al. Can body mass index accurately predict adiposity in newborns? Arch Dis Child Fetal Neonatal Ed. 2014;99:F238-9.

19. MGRS WHO. WHO child growth standards: length/height for age, weightfor-age, weight-for-length, weight-for-height and body mass index-for-age, methods and development. Geneva: World Health Organization; 2006.

20. Addo OY, Himes JH. Are field measures of adiposity sufficient to establish fatness-related linkages with metabolic outcomes in adolescents? Eur J Clin Nutr. 2014;68:671-6.

21. Wohlfahrt-Veje C, Tinggaard J, Winther K, Mouritsen A, Hagen CP, Mieritz MG, et al. Body fat throughout childhood in 2647 healthy Danish children : agreement of BMI , waist circumference, skinfolds with dual X-ray absorptiometry. Eur J Clin Nutr 2014; 68:664-670. doi:https://doi.org/10.1038/ejen.2013.282.
22. Boeke CE, Oken E, Kleinman KP, Rifas-Shiman SL, Taveras EM, Gillman MW. Correlations among adiposity measures in school-aged children. BMC Pediatr. 2013;13:99. https://doi.org/10.1186/1471-2431-13-99.

23. Lohman TG, Roche AF, Martorell R. Anthropometric standardization reference manual: Human kinetics books Champaign; 1988.

24. Naini FB. The Frankfort plane and head positioning in facial aesthetic analysis-the perpetuation of a myth. JAMA Facial Plastic Surgery. 2013.

25. Urlando A, Dempster P, Aitkens S. A new air displacement plethysmograph for the measurement of body composition in infants. Pediatr Res. 2003;53:486-92.

26. Ma G, Yao M, Liu Y, Lin A, Zou H, Urlando A, et al. Validation of a new pediatric air-displacement plethysmograph for assessing body composition in infants. Am J Clin Nutr. 2004;79:653-60. https://doi.org/10.1093/ajcn/79.4.653.

27. Freedman DS, Ogden CL, Berenson GS, Horlick M. Body mass index and body fatness in childhood. Curr Opin Clin Nutr Metab Care. 2005;8:618-23 https://www.ncbi.nlm.nih.gov/pubmed/16205462.

28. UNICEF. WHO: Indicators for assessing infant and young child feeding practices. Part 1 Definitions. 2008.

29. Eriksson B, Löf M, Forsum E. Body composition in full-term healthy infants measured with air displacement plethysmography at 1 and 12 weeks of age. Acta Paediatr Int J Paediatr. 2010.

30. Koontz MB, Gunzler DD, Presley L, Catalano PM. Longitudinal changes in infant body composition: association with childhood obesity. Pediatr Obes. 2014;9:e141-4.

31. Hernández Ávila M, Rivera Dommarco J, Shamah Levy T, Cuevas Nasu L, Gómez Acosta LM, Gaona Pineda EB, et al. Encuesta Nacional de Salud y Nutrición de Medio Camino 2016. México: Cuernavaca; 2016.

32. Berrington de Gonzalez A, Hartge P, Cerhan JR, Flint AJ, Hannan L, Maclnnis RJ, et al. Body-Mass Index and Mortality among 1.46 Million White Adults. N Engl J Med. 2010;363:2211-9. doi:https://doi.org/10.1056/NEJMoa1000367.

33. Mei Z, Grummer-Strawn LM, Pietrobelli A, Goulding A, Goran MI, Dietz WH. Validity of body mass index compared with other bady-composition screening indexes for the assessment of body fatness in children and adolescents. Am J Clin Nutr. 2002;75:978-85.

34. Maynard LM, Wisemandle W, Roche AF, Chumlea WC, Guo SS, Siervogel RM. Childhood body composition in relation to body mass index. Pediatrics. 2001;107: 344-50 http://www.ncbi.nlm.nih.gov/pubmed/11158468. Accessed 29 Nov 2018.

35. Weber DR, Moore RH, Leonard MB, Zemel BS. Fat and lean BMl reference curves in children and adolescents and their utility in identifying excess adiposity compared with BMI and percentage body fat. Am J Clin Nutr. 2013;98:49-56. https://doi.org/10.3945/ajcn.112.053611.

36. Vanderwall C, Randall Clark R, Eickhoff J, Carrel AL. BMI is a poor predictor of adiposity in young overweight and obese children. BMC Pediatr. 2017;17: 135. https://doi.org/10.1186/s12887-017-0891-z.

37. Craig E, Reilly J, Bland R. Body fatness or anthropometry for assessment of unhealthy weight status? Comparison between methods in south African children and adolescents. Public Health Nutr. 2012;16:2005-13.

38. Freedman DS, Ogden CL, Blanck HM, Borrud LG, Dietz WH. The abilities of body mass index and skinfold thicknesses to identify children with low or elevated levels of dual-energy X-ray absorptiometry-determined body fatness. J Pediatr. 2013;163:160-6. https://doi.org/10.1016/j.jpeds.2012.12.093.

39. Bell KA, Wagner CL, Perng W, Feldman HA, Shypailo RJ, Belfort MB. Validity of Body Mass Index as a Measure of Adiposity in Infancy. J Pediatr. 2018;196: 168-174.e1. doi:https://doi.org/10.1016/j.jpeds.2018.01.028.

40. Alves Junior CA, Mocellin MC, Gonçalves ECA, Silva DA, Trindade EB. Anthropometric indicators as body fat discriminators in children and adolescents: a systematic review and meta-analysis. Adv Nutr. 2017:8:71827. https://doi.org/10.3945/an.117.015446.

41. Perng W, Ringham BM, Glueck DH, Sauder KA, Starling AP, Belfort MB, et al. An observational cohort study of weight- and length-derived anthropometric indicators with body composition at birth and $5 \mathrm{mo}$ : the healthy start study. Am J Clin Nutr. 2017;106:559-67. https://doi.org/10. 3945/ajcn.116.149617.

42. Tuan NT, Wang Y. Adiposity assessments: Agreement between dual-energy $X$-ray absorptiometry and anthropometric measures in U.S. children. Obesity. 2014;22:1495-504.

43. Després J-P. Body fat distribution and risk of cardiovascular disease: an update. Circulation. 2012;126:1301-13. https://doi.org/10.1161/ CIRCULATIONAHA.111.067264.

44. Santos S, Gaillard R, Oliveira A, Barros H, Abrahamse-Berkeveld M, van der Beek EM, et al. Associations of infant subcutaneous fat mass with Total and 
abdominal fat mass at school-age: the generation R study. Paediatr Perinat Epidemiol. 2016;30:511-20. https://doi.org/10.1111/ppe.12307.

45. Jensen NS, Camargo TF, Bergamaschi DP. Comparison of methods to measure body fat in 7-to-10-year-old children: a systematic review. Public Health. 2016;133:3-13.

46. Marrodán M, Alvarez JM, de Espinosa MG-M, Carmenate M, López-Ejeda N, Cabañas $\mathrm{M}$, et al. Predicting percentage body fat through waist-to-height ratio (WtHR) in Spanish schoolchildren. Public Health Nutr. 2014;17:870-6. https://doi.org/10.1017/S1368980013000888.

47. Pereira-da-Silva L, Dias MP-G, Dionísio E, Virella D, Alves M, Diamantino C, et al. Fat mass index performs best in monitoring management of obesity in prepubertal children. J Pediatr. 2016;92:421-6. https://doi.org/10.1016/j.jped. 2015.11.003.

48. Goswami I, Rochow N, Fusch G, Liu K, Marrin ML, Heckmann M, et al. Length normalized indices for fat mass and fat-free mass in preterm and term infants during the first six months of life. Nutrients. 2016;8:417. https:// doi.org/10.3390/nu8070417.

49. Wells JC. A critique of the expression of paediatric body composition data. Arch Dis Child. 2001;85:67-72 https://www.ncbi.nlm.nih.gov/pubmed/ 11420208.

Ready to submit your research? Choose BMC and benefit from:

- fast, convenient online submission

- thorough peer review by experienced researchers in your field

- rapid publication on acceptance

- support for research data, including large and complex data types

- gold Open Access which fosters wider collaboration and increased citations

- maximum visibility for your research: over $100 \mathrm{M}$ website views per year

At $\mathrm{BMC}$, research is always in progress.

Learn more biomedcentral.com/submissions 